\title{
In vitro Induction and Proliferation of Callus from Immature Cotyledons and Embryos of Juglans regia cv. 'Xiangling'
}

\author{
Xiao-Dong CAI*, Gui-Yuan WANG, Wen-Juan CAO \\ Yangtze University, College of Horticulture and Gardening, Jingzhou, Hubei, P.R. China; caixiao.dong@163.com ( ${ }^{*}$ corresponding author)
}

\begin{abstract}
Callus holds great potential for biotechnology applications in plants. In this study, several experiments were performed to establish a protocol for in vitro induction of good quality callus by using immature cotyledons and embryos of Juglans regia cv. 'Xiangling' as the explants. DKW basal media supplemented with different concentrations of plant growth regulators were applied to determine the induction rate, texture and color of the recovered callus. Results showed that the optimum culture medium for the callus induction from these explants was a DKW basal medium consisting of $1 \mathrm{mg} / \mathrm{L} \mathrm{BA}, 2 \mathrm{mg} / \mathrm{L} \mathrm{KT} 250 \mathrm{mg} / \mathrm{L}$ glutamine, $500 \mathrm{mg} / \mathrm{L}$ casein hydrolysate, 200 $\mathrm{mg} / \mathrm{L} \mathrm{Vc}, 50 \mathrm{~g} / \mathrm{L}$ sucrose and $2.8 \mathrm{~g} / \mathrm{L}$ Gelrite (i.e., the T8 medium). The average rate of callus induction on the medium reached 80.7\% for the immature cotyledons and $66.7 \%$ for the immature embryos, and all the callus was characterized by a friable, creamy or yellow appearance. In vitro proliferation of callus was not very successful as a result of the fact that the friable callus with creamy or yellow color grew very slowly, whereas the fast-growing callus was easy to turn brown and died eventually. Even though further investigation will be required to overcome the problem of browning and assess the regeneration ability of the callus, this approach for the production of friable callus may have valuable applications for walnut and other woody trees.
\end{abstract}

Keywords: browning, callus induction rate, somatic embryogenesis, tissue culture, walnut

\section{Introduction}

The common walnut (Juglans regia), one of the ancestral species of Juglans, is a popular fruit crop with a potential for nut production, as it is abundant in nutritious substances and dietary minerals (Vahdati et al., 2008, 2009). Walnut has also been considered as a valuable tree species owning to its use for forestry in the world. In general practice, walnut is usually propagated by seeds and can also be vegetatively propagated via graft and cutting method. Propagation by seeds is undesirable because of high heterozygosis and long growth period of the seedlings. Grafting the scion cultivars onto a rootstock is another general way for walnut clonal propagation, but it was reported to be labor-intensive, time-consuming and costly (Rezaee et al., 2008). Cutting technique was also extensively employed in walnut, but the main difficulty of this method was related to low rooting ability of the nodal segments from mature trees (Payghamzadeh and Kazemitabar, 2011). Since the first report on in vitro stem culture of black walnut (J. nigra) (Cummins and Ashby, 1969), the potential of in vitro propagation of walnut initiated from apical buds, nodal segments, leaves, petioles, cotyledons or embryos has been widely explored during the past four decades. Most of these researches focused on browning phenomenon, shoot or bud elongation, root induction, embryo germination or somatic embryogenesis (Fernández et al., 2000; Vahdati et al., 2006, 2008, 2009; Amiri, 2006; Fatima et al., 2006; Leal et al., 2007; Avilés et al., 2009; Toosi and Dilmagani, 2010; Payghamzadeh and Kazemitabar, 2010, 2011; Amiri and Gharati, 2012; Gotea et al., 2012). In spite of its recalcitrant behavior under in vitro conditions, plant tissue culture provides an alternative approach for propagation of walnut species.

Advanced biotechnology has attracted considerable attention in diverse plants. A basic prerequisite of biotechnology application is the availability of a reliable in vitro regeneration protocol. As it is well known, plants can be regenerated from callus cultures via somatic embryogenesis or adventitious shoot organogenesis. Somatic embryogenesis is used as a model system for large-scale vegetative propagation of a wide range of plants species (von Arnold et al., 2002) including some forest trees (Lelu-Walter et al., 2013). In walnut, previous reports suggested that somatic embryogenesis could be induced from immature cotyledons, embryos, embryonic axes and endosperm on an appropriate medium (Tulecke et al., 1988; Tang et al., 2000; Fernández et al., 2000; Vahdati et al., 2006; Fatima et al., 2006; Toosi and Dilmagani, 2010; Payghamzadeh and Kazemitabar, 2011). Callus was always used as initial material to produce somatic embryoids (Aftab, 2012) and adventitious shoots (Tang and Newton, 2005) in many woody plants, but this has not been documented in walnut. A lack of good quality callus may be a major bottleneck to successful regeneration of somatic embryoids or shoots from callus in walnut.

Callus is an attractive target explant for studying germplasm and improvement of plant cultivars, such as so- 
maclonal variations, somatic hybridization and genetic transformation, etc. Therefore, in order to apply advanced biotechnology in these research fields, it is essential to develop an efficient callus induction system of walnut. The success of callus induction is to a large extent determined by the genotype, the developmental stage and types of explants, and the nutrients and plant growth regulators provided by the culture medium. Generally speaking, callus may arise from proliferating cells of the parent tissue by placing explants of appropriate size on a growth-supporting medium under sterile conditions. In walnut, callus has been induced from young plant tissue like endosperm (Tulecke et al., 1988), immature cotyledons (Neuman et al., 1993; Long et al., 1995; San and Dumanoglu, 2006), embryos (Breton et al., 2004; Toosi and Dilmagani, 2010 ) and embryonic axes (Tang et al., 2000; Fernández et al., 2000) and even from leaf explants (Farsi et al., 2012). Culture conditions such as basal medium and auxin/cytokinin ratio are also important factors to be responsible for callus formation. For example, Neuman et al. (1993) found that the concentration of 2, 4-D and TDZ played an important role in callus production from walnut cotyledons. Fernández et al. (2000) emphasized that 2, 4-D was less effective at inducing callus than NAA or IBA, and they believed that auxins facilitated callus formation in walnut. According to the report of Payghamzadeh and Kazemitabar (2010), callus fresh weight of walnut depended on the concentration of BAP and IBA, and the 0.01 and 0.1 $\mathrm{mg} / \mathrm{L} \mathrm{IBA} \mathrm{as} \mathrm{well} \mathrm{as} 1.5 \mathrm{mg} / \mathrm{L}$ BAP favored callus induction from immature embryonic bodies. Although efforts have been made to improve the protocol of callus induction of walnut, so far it is still a quite difficult task and far from being solved. Thus, further investigation will be needed to establish a perfect induction system of walnut callus. Herein, in vitro callus induction from the immature cotyledons and embryos of J.regia cv. 'Xiangling' was studied in response to the DKW basal media supplemented by different concentrations and types of plant growth regulators. Most efforts were directed towards establishing a feasible protocol for the induction and multiplication of walnut callus by numerical investigation and morphological characterization of the callus.

\section{Materials and methods}

\section{Plant materials}

The open pollinated fruits of J.regia cv. 'Xiangling' were harvested at around 8 weeks post-anthesis and prechilled at $4{ }^{\circ} \mathrm{C}$ for 20 days before the experiment was conducted, as pretreatment with low temperature may improve the efficiency of callus induction.

\section{Disinfection of explants}

Firstly the fruit exocarps were removed and the remaining parts of the fruits were rinsed thoroughly under running tap water for $60 \mathrm{~min}$ to eliminate phenolic compounds. Then the remains of the fruits were surface-sterilized by immersion in $70 \%$ of ethanol for $5 \mathrm{~min}$ followed by disinfection with $2 \%$ hypochlorite sodium solution plus $0.01 \%$ Tween 20 for $15 \mathrm{~min}$. Thereafter the samples were rinsed 5 times with sterile distilled water. Prior to inoculation, immature cotyledons and embryos were carefully dissected out from the sterile fruits through the suture at the pedicel end using a sharp-pointed forceps and a scalpel blade.

\section{Callus induction}

In the present study, the explants were cultured on 13 different media (as shown in Tab.1), i.e., solidified DKW basal media (Driver and Kuniyuki, 1984) supplemented

Tab. 1. Effects of different concentrations of plant growth regulators on induction rate, texture and color of callus from immature cotyledons of J. regia cv. 'Xiangling'

\begin{tabular}{|c|c|c|c|c|c|c|c|c|}
\hline \multirow[t]{2}{*}{ Treatment } & \multicolumn{5}{|c|}{ Plant growth regulators $(\mathrm{mg} / \mathrm{L})$} & \multirow[t]{2}{*}{$\begin{array}{c}\text { Callus } \\
\text { induction } \\
(\%)\end{array}$} & \multicolumn{2}{|c|}{ Callus } \\
\hline & NAA & $\mathrm{BA}$ & $2,4-\mathrm{D}$ & KT & TDZ & & Texture & Color \\
\hline $\mathrm{CK}$ & 0 & 0 & 0 & 0 & 0 & $0 \quad \mathrm{f}$ & / & I \\
\hline $\mathrm{T} 1$ & 1 & 0 & 0 & 0 & 0 & $32.6 \pm 3.4^{d}$ & Compact & Brown \\
\hline $\mathrm{T} 2$ & 2 & 0 & 0 & 0 & 0 & $49.6 \pm 5.6 \mathrm{bc}$ & Friable & Creamy \\
\hline T3 & 0 & 1 & 0 & 0 & 0 & $57.88 \pm 6.7^{b}$ & Compact & Green \\
\hline $\mathrm{T} 4$ & 0 & 2 & 0 & 0 & 0 & $55.6 \pm 6.7 \mathrm{~b}$ & Compact & Brown \\
\hline $\mathrm{T} 5$ & 0 & 0 & 1 & 0 & 0 & $43.7 \pm 5.6^{c}$ & Friable & Creamy \\
\hline T6 & 0 & 0 & 2 & 0 & 0 & $71.9 \pm 9.0^{a}$ & Semi-compact & Green \\
\hline $\mathrm{T} 7$ & 1 & 1.5 & 0 & 0 & 0 & $73.3 \pm 10.1^{\text {a }}$ & Compact & Green \\
\hline T8 & 0 & 1 & 0 & 2 & 0 & $80.7 \pm 8.9$ a & Friable & Creamy \\
\hline T9 & 0 & 2 & 0 & 3 & 0 & $67.9 \pm .6 .8$ a & Friable & Creamy \\
\hline $\mathrm{T} 10$ & 0 & 1 & 2 & 1 & 0 & $23.0 \pm 4.6^{\mathrm{c}}$ & Semi-compact & Brown \\
\hline $\mathrm{T} 11$ & 0 & 1 & 0 & 0 & 1 & $56.3 \pm 6.8$ b & Semi-compact & Brown \\
\hline $\mathrm{T} 12$ & 0 & 0 & 1 & 0 & 1 & $29.6 \pm 4.6 \mathrm{dc}$ & Semi-compact & Brown \\
\hline
\end{tabular}

Note: Mean values with the same letters are not significant differences (LSD test, $\mathrm{p}<0.05$ ) 
380

with different concentrations of plant growth regulators (NAA, BA, 2, 4-D, KT or TDZ), designed especially to facilitate callus induction of walnut according to previous reports (Long et al., 1995; Tang et al., 2000; Fernández et al., 2000; Breton et al., 2004; San and Dumanoglu, 2006; Toosi and Dilmagani, 2010; Farsi et al., 2012). All media contained $250 \mathrm{mg} / \mathrm{L}$ glutamine, $500 \mathrm{mg} / \mathrm{L}$ casein hydrolysate, $200 \mathrm{mg} / \mathrm{L} \mathrm{Vc}, 50 \mathrm{~g} / \mathrm{L}$ sucrose and $2.8 \mathrm{~g} / \mathrm{L}$ Gelrite (Sigma), $\mathrm{pH}$ 5.8. For the immature cotyledons, the explants were cut into pieces around $0.5 \mathrm{~cm}^{2}$ and placed horizontally on the medium. The experimental design was completely randomized, and five 100-ml Erlenmeyer flasks containing $40 \mathrm{ml}$ medium were used for each treatment with four explants per flask. For the culture of immature embryos, the explants were aseptically removed from the fruits and oriented with their apical ends protruding from the medium (only one explant per flask), and two replicates each with nine or ten embryos were used for each treatment. All cultures were incubated at $25^{\circ} \mathrm{C}$ and $12 \mathrm{~h} / 12 \mathrm{~h}$ (light/dark) cycles under cool white fluorescent lamps (2500 Lux). 30 days later, the appropriate induction media were selected based on the results of the induction rate, texture and color of the recovered callus. The regenerated cultures were transferred to fresh medium for further induction of callus.

\section{Callus proliferation}

In order to obtain much more callus, callus proliferation was also performed in this study. About $0.3 \mathrm{~g}$ callus of good quality was picked up carefully and transferred to fresh media. Five flasks were used for each treatment, and the experiment was replicated three times. The callus was harvested at 20 days after culture and fresh weight was measured.

\section{Experimentation and data analysis}

All experiments were carried out as a complete randomized design. DATA analysis was performed using the SPSS 16.0. Prior to analysis, data of callus induction rate were arcsin-square root transformed. Variance analysis and means comparison were done using the LSD test (ANOVA). P-values $<0.05$ were consid $\neg$ ered statistically significant.

\section{Results and discussion}

\section{Callus induction from the immature cotyledons}

After 3 days of culture, the excised immature cotyledons gradually changed color from white to green on all media, and the initiation of callus was observed around the cut edge of the explants after another one week of culture on all media except medium CK, the control. The induction rate, texture and color of the induced callus were different with respect to different media tested 30 days later (Tab.1). In spite that a portion of regenerated cultures slowly became brown in color and even died at last, callus could be observed in all treatments with the exception of the control (Fig.1A). However, most of the calls was compact or semi-compact with a green or brown color (Fig.1B, C and $\mathrm{D}$ ), and friable callus was only observed on the media T2, T5, T8 (Fig.1F) and T9 (Fig.1E). Somatic embryoids were also occurred on the T9 medium (arrow indicated in Fig.1E), although the induction rate was very low in the present research. The mean rate of callus induction on the T8 medium reached $80.7 \%$, which was the highest percentage among all the treatments. The statistical analysis indicated that the mean callus induction rates were not significantly different in response to the treatments $\mathrm{T} 6$, T7, T8 and T9, but all of them had significantly higher rates of callus induction than the rest medium $(\mathrm{P}<0.005)$ . Taking into account the induction rate and the quality of the callus, both the T8 and T9 medium were the appropriate media for callus induction from the immature cotyledons of J. regia cv. 'Xiangling.'
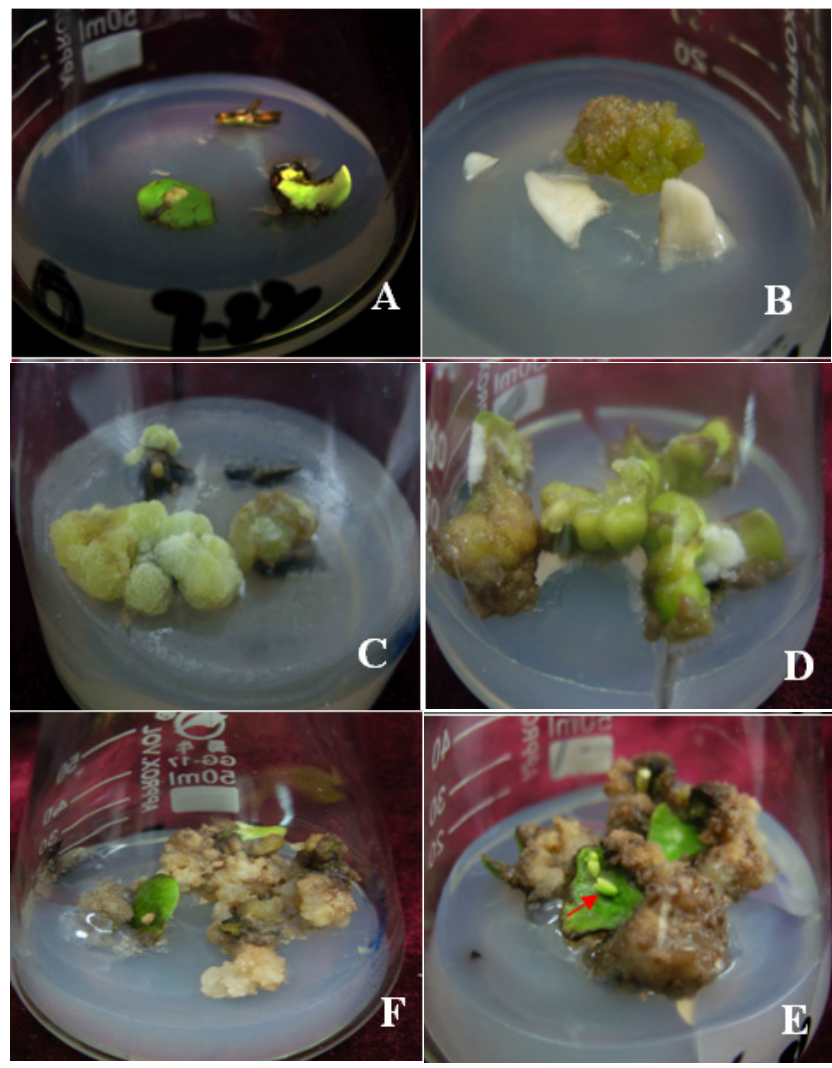

Fig. 1. In vitro induction of callus from immature cotyledons of J. regia cv. 'Xiangling' on solidified DKW basal media supplemented with $250 \mathrm{mg} / \mathrm{L}$ glutamine, $500 \mathrm{mg} / \mathrm{L}$ casein hydrolysate, $200 \mathrm{mg} / \mathrm{L} \mathrm{Vc}, 50 \mathrm{~g} / \mathrm{L}$ sucrose, $3 \mathrm{~g} / \mathrm{L}$ Gelrite (Sigma) and different concentrations of plant growth regulators. (A) Explants cultured on the CK medium. (B) Semi-compact callus with a green color induced on the T6 medium containing $2 \mathrm{mg} / \mathrm{L}$ 2, 4-D; (C) Compact and light green callus induced on T3 medium containing $1 \mathrm{mg} / \mathrm{L} \mathrm{BA}$; (D) Compact and green callus induced on T7 medium containing $1 \mathrm{mg} / \mathrm{L} \mathrm{NAA}$ and $1.5 \mathrm{mg} / \mathrm{L} \mathrm{BA}$; (E) Embryos (arrow indicated) and friable callus regenerated on T9 medium containing 2 $\mathrm{mg} / \mathrm{L} \mathrm{BA}$ and $3 \mathrm{mg} / \mathrm{L} \mathrm{KT}$; (F) Friable and creamy callus regenerated on T8 medium containing $1 \mathrm{mg} / \mathrm{L} \mathrm{BA}$ and $2 \mathrm{mg} / \mathrm{L} \mathrm{KT}$ 
Callus induction from the immature embryos

Four media (T2, T5, T8 and T9) for effective induction of friable callus and the CK (as a control) were chosen to regenerate callus from immature walnut embryos. Generally, the immature embryos turned green after 4 days of culture (Fig.2A). Almost all immature embryos were germinated on all the media after 30 days of culture.
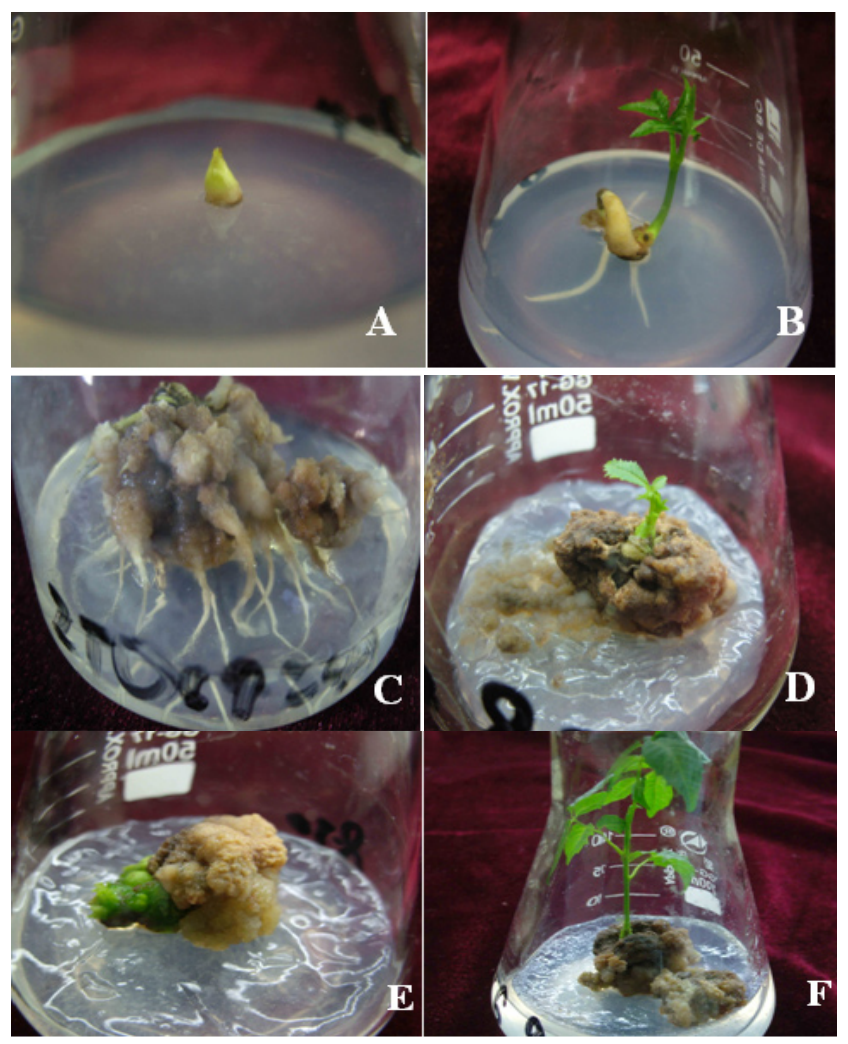

Fig. 2. In vitro culture of immature embryos of J. regia cv. 'Xiangling' on solidified DKW basal media supplemented with $250 \mathrm{mg} / \mathrm{L}$ glutamine, $500 \mathrm{mg} / \mathrm{L}$ casein hydrolysate, $200 \mathrm{mg} / \mathrm{L} \mathrm{Vc}, 50 \mathrm{~g} / \mathrm{L}$ sucrose, $3 \mathrm{~g} / \mathrm{L}$ Gelrite (Sigma) and different concentrations of plant growth regulators. (A) An embryo after 4 days of culture; (B) Regenerated plants after 18 days of culture on CK medium (C) Developed roots but no shoot and callus on T2 medium containing $2 \mathrm{mg} / \mathrm{L} \mathrm{NAA}$; (D) Regenerated callus and a green shoot induced on $\mathrm{T} 5$ medium containing $1 \mathrm{mg} / \mathrm{L} 2,4-\mathrm{D}$; (E) Regenerated friable callus with a yellow color and malformed shoots on T8 medium containing $1 \mathrm{mg} / \mathrm{L} \mathrm{BA}$ and $2 \mathrm{mg} / \mathrm{L} \mathrm{KT}$; (F) Regenerated friable callus with a dark yellow color and plants without a root system on $\mathrm{T} 9$ medium containing $2 \mathrm{mg} / \mathrm{L} \mathrm{BA}$ and $3 \mathrm{mg} / \mathrm{L} \mathrm{KT}$
However, different culture media had profound effects on the development of the embryos. The regenerated products had roots and shoots when cultured on the control medium (Fig.2B), and had several roots and no shoot on the T2 medium (Fig.2C), whereas shoots without a root was observed on the rest three media (Fig.2D, E and F). The entire callus appeared creamy in color at the beginning of culture, but later gradually became yellow and even dark yellow. As shown in tab.2, callus formation could be observed on all media except the control, and the maximum percentage $(66.7 \%)$ of callus induction was achieved on the T8 medium. One-way ANOVA analysis revealed that the mean rate of callus induction on T8 medium was significant higher $(\mathrm{P}<0.005)$ than those on others.

\section{Callus induction from the regenerated compact/semi- compact callus}

Friable callus has been proven to be crucial for the establishment of cell suspension cultures, which played an important role in successful somatic hybridization (Davey et al., 2005) and genetic transformation (Chumakov and Moiseeva, 2012) in many plants. In this study, the compact callus or semi-compact callus was separated from the cultures carefully and were cutted into appropriate pieces with a diameter of 3-5 $\mathrm{mm}$ with a sharp-pointed forceps and a scalpel blade, and then placed on the tested media, T2, T5, T8 and T9. After 20 days of culture, it was possible to obtain fresh callus from most of the compact callus or semi-compact callus under all the culture conditions, and its texture and color were variable depending on the concentration and the kind of plant growth regulators. When cultured on the T2 medium, the callus had a semi-compact aspect with a yellowish color (Fig.3A). The creamy callus with a soft texture was observed both on the medium T9 (Fig.3B) and T8 (Fig.3C). Unfortunately, the callus on the culture medium $\mathrm{T} 5$ showed a compact appearance with a yellow and green color (Fig.3D).

\section{Proliferation of induced walnut callus}

To screen the optimum medium for callus multiplication, about $0.3 \mathrm{~g}$ friable callus with creamy color was picked up carefully and transferred to fresh T2, T5, T8 and T9 medium and the CK, respectively. As showed in Tab.3, the mean weight of the fresh callus ranged from $0.64 \mathrm{~g}$

Tab. 2. Effects of different concentrations of plant growth regulators on the induction rate, texture and color of callus from immature embryos of J. regia cv. 'Xiangling

\begin{tabular}{|c|c|c|c|c|c|c|c|}
\hline \multirow[t]{2}{*}{ Treatment } & \multicolumn{4}{|c|}{ Plant growth regulators $(\mathrm{mg} / \mathrm{L})$} & \multirow[t]{2}{*}{$\begin{array}{l}\text { Callus } \\
\text { induction }(\%)\end{array}$} & \multicolumn{2}{|c|}{ Callus } \\
\hline & NAA & BA & 2,4-D & KT & & Texture & Color \\
\hline $\mathrm{CK}$ & 0 & 0 & 0 & 0 & $0 \mathrm{c}$ & / & / \\
\hline $\mathrm{T} 2$ & 2 & 0 & 0 & 0 & $40.6 \pm 4.4^{b}$ & Friable & Dark yellow \\
\hline T5 & 0 & 0 & 1 & 0 & $33.4 \pm 7.9^{b}$ & Friable & Yellow \\
\hline $\mathrm{T} 8$ & 0 & 1 & 0 & 2 & $66.7 \pm 7.9^{\mathrm{a}}$ & Friable & Yellow \\
\hline T9 & 0 & 2 & 0 & 3 & $46.9 \pm 4.4^{b}$ & Friable & Dark yellow \\
\hline
\end{tabular}

Note: Mean values with the same letters are not significant differences (LSD test, $\mathrm{p}<0.05$ ) 
Tab. 3. Effects of different media on proliferation of the induced callus of J. regia cv. 'Xiangling'

\begin{tabular}{cccccccc}
\hline \multirow{2}{*}{ Treatment } & \multicolumn{1}{c}{ Plant growth regulators $(\mathrm{mg} / \mathrm{L})$} & & \multicolumn{2}{c}{$\begin{array}{c}\text { Callus fresh } \\
\text { weight }(\mathrm{g} / \text { flask })\end{array}$} & \multicolumn{2}{c}{ Callus } \\
& NAA & BA & $2,4-\mathrm{D}$ & KT & & Texture & Color \\
CK & 0 & 0 & 0 & 0 & $0.75 \pm 0.08^{\mathrm{c}}$ & friable & Creamy \\
T2 & 2 & 0 & 0 & 0 & $0.64 \pm 0.06^{\mathrm{c}}$ & friable & Creamy \\
T5 & 0 & 0 & 1 & 0 & $2.03 \pm 0.14^{\mathrm{a}}$ & friable & Brown \\
T8 & 0 & 1 & 0 & 2 & $1.18 \pm 0.05^{\mathrm{b}}$ & friable & yellow \\
\hline T9 & 0 & 2 & 0 & 3 & $1.25 \pm 0.12^{\mathrm{b}}$ & Water-soaked & yellow \\
\hline
\end{tabular}

Note: Mean values with the same letters are not significant differences (LSD test, $\mathrm{p}<0.05$ )

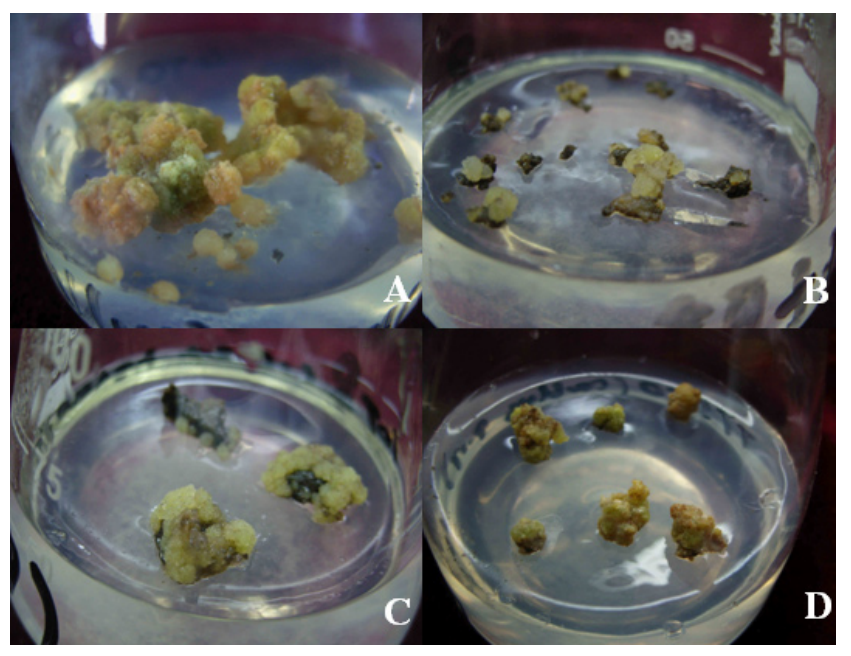

Fig. 3. Induction of callus from the compact callus or semi-compact callus of J. regia cv. 'Xiangling'on DKW basal media supplemented with 250 $\mathrm{mg} / \mathrm{L}$ glutamine, $500 \mathrm{mg} / \mathrm{L}$ casein hydrolysate, $200 \mathrm{mg} / \mathrm{L} \mathrm{Vc}, 50 \mathrm{~g} / \mathrm{L}$ sucrose, $3 \mathrm{~g} / \mathrm{L}$ Gelrite (Sigma) and different concentrations of plant growth regulators. (A) Regenerated semi-compact callus with a yellowish color on T2 medium containing $2 \mathrm{mg} / \mathrm{L}$ NAA; (B) Creamy callus with a soft texture induced on T8 medium containing $1 \mathrm{mg} / \mathrm{L}$ BA and 2 $\mathrm{mg} / \mathrm{L} \mathrm{KT}$; (C) Creamy callus with a soft texture induced on T9 medium containing $2 \mathrm{mg} / \mathrm{L} \mathrm{BA}$ and $3 \mathrm{mg} / \mathrm{L} \mathrm{KT}$; (D) Compact callus induced on T5 medium containing $1 \mathrm{mg} / \mathrm{L} 2$, 4-D

per flask to $2.03 \mathrm{~g}$ per flask. The T9 medium containing 1 $\mathrm{mg} / \mathrm{L} 2$, 4-D seemed to be the most efficient on multiplication of the callus, and the mean weight of the fresh callus increased over 10 folds and reached 2.093 g per flask, with a significant higher level than those of other treatments $(\mathrm{P}<0.005)$. However, the callus on the T5 medium was water-soaked and presented a greater degree of browning (Fig. 4A). On the T8 (Fig. 4B) and T9 (Fig. 4C) medium, most of the callus grew quickly, with a friable and yellow appearance, and a portion of callus died 20 days after culture initiation as a result of browning. The callus cultured on the T2 (Fig. 4D) and the control medium (Fig. 4E) was not as abundant as that on the above-mentioned media, but it had a friable texture with less browning. All of these indicated that the adopted media were not optimum for callus proliferation owning to the fact that rapid-growing callus turned brown easily, and callus of good quality developed very slowly in the study.
Callus can probably be obtained in all plant species provided that the appropriate explant types, culture media compositions and cultural environmental conditions are employed. Walnut is extensively distributed throughout the world. Although efforts have been made to induce callus in walnut as described above, it is far from being completely comprehended. Therefore, this research focused on callus induction from the immature cotyledons, immature embryos and the compact or semi-compact callus (regenerated from the former two types of explants) in J. regia cv. 'Xiangling.' According to the above results, friable callus

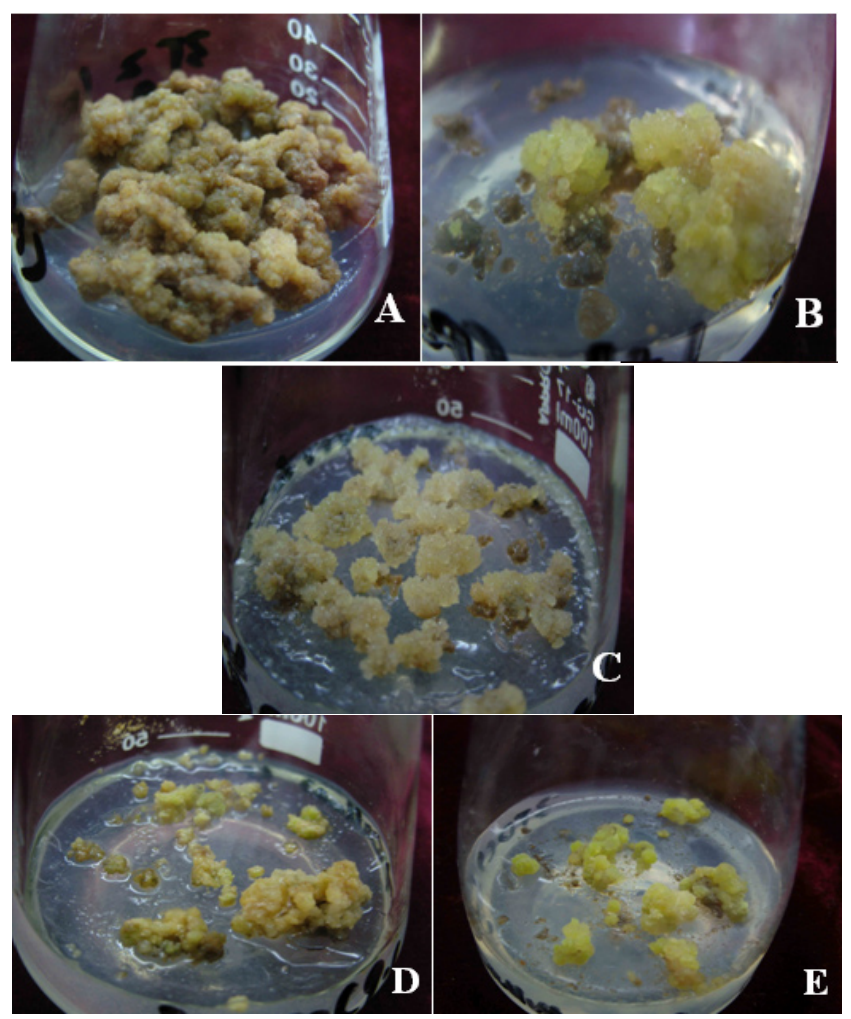

Fig. 4. Proliferation of callus of J. regia cv. 'Xiangling' on DKW basal media supplemented with $250 \mathrm{mg} / \mathrm{L}$ glutamine, $500 \mathrm{mg} / \mathrm{L}$ casein hydrolysate, $200 \mathrm{mg} / \mathrm{L} \mathrm{Vc}, 50 \mathrm{~g} / \mathrm{L}$ sucrose, $3 \mathrm{~g} / \mathrm{L}$ Gelrite (Sigma) and different concentrations of plant growth regulators. (A) Water-soaked and browning callus on T5 medium containing $1 \mathrm{mg} / \mathrm{L} 2$, 4-D; (B\&C) Friable and yellow callus on T8 medium containing $1 \mathrm{mg} / \mathrm{L} \mathrm{BA}$ and 2 $\mathrm{mg} / \mathrm{L} \mathrm{KT}$ (B) and T9 medium containing $2 \mathrm{mg} / \mathrm{L} \mathrm{BA}$ and $3 \mathrm{mg} / \mathrm{L} \mathrm{KT}$ (C); (D\&E) Friable and creamy callus on T2 medium containing $2 \mathrm{mg} / \mathrm{L}$ NAA (D) and CK medium (E) 
was achieved when these explants was cultured on the T2, T5, T8 and T9 medium in this study. However, as shown in Tab. 1, 2 and 3, most of induced callus was easy to turn brown, and browning also occurred during the course of callus proliferation. Browning is one of the major obstacles in walnut tissue culture, and it is attributed to the production of high concentrations of phenolic compounds which can be easily oxidized (Payghamzadeh and Kazemitabar, 2011). In the present study, although $200 \mathrm{mg} / \mathrm{L} \mathrm{Vc}$ was used as an antioxidant to alleviate or avoid browning, the phenomenon occurred all the same. Previous reports suggested that frequent subculturing or incubating cultures in total darkness after inoculation could overcome the problem of browning in plant tissue cultures (Long et al., 1995; Payghamzadeh and Kazemitabar, 2011). Some other measures should be adopted to solve the problem of browning in future research.

Callus has the potential to differentiate into a plant by a direct or indirect way, and good quality callus is of great value for research on germplasm and improvement in plants. In general, embryogenic callus has been considered as an ideal initial tissue for biotechnological researches such as induced mutation in vitro, genetic improvement and protoplast manipulation. Embryogenic callus could be obtained from the youngest anthers (Prado et al., 2010), embryos (Tang and Newton, 2005) and ovules (Cardoso et al., 2012) in a number of woody trees. In the present paper, we obtained callus from the immature cotyledons, immature embryos and the compact or semi-comapct callus of walnut. However, it is a fact that walnut is one of the most recalcitrant species in vitro. Many problems like easy browning, poor proliferation, bad elongation and difficult rooting, are always obstacles for walnut propagation by tissue culture. In this study, the responses of the callus to all adopted media during the course of multiplication were not very satisfying as a result of the fact that the color of rapid-growing callus was easy to turn brown, whereas the callus in good quality developed very slowly. Farsi et al. (2012) suggested that somatic embryoids induction from callus was more difficult than from immature cotyledons, zygote embryos and endosperm in J. regia. Therefore, further investigation is needed to examine the regeneration capacity of the callus induced in this study.

\section{Conclusion}

In conclusion, friable callus with a creamy or yellow color was induced from the immature cotyledons, the immature embryos and the compact or semi-compact callus (regenerated from the former two types of explants) in J. regia cv. 'Xiangling'. The T8 medium, i.e. solidified DKW basal media plus $1 \mathrm{mg} / \mathrm{L} \mathrm{BA}, 2 \mathrm{mg} / \mathrm{L} \mathrm{KT}, 250 \mathrm{mg} / \mathrm{L}$ glutamine, $500 \mathrm{mg} / \mathrm{L}$ casein hydrolysate, $200 \mathrm{mg} / \mathrm{L} \mathrm{Vc}, 50$ $\mathrm{g} / \mathrm{L}$ sucrose and $2.8 \mathrm{~g} / \mathrm{L}$ Gelrite, was optimum for callus induction from these explants in this study. The adopted media were not very appropriate for in vitro multiplica- tion of the callus because callus of good quality grew very slowly, whereas the fast-growing callus was easy to turn brown and even died eventually. Further investigation is required to overcome the problem of browning and evaluate the regeneration ability of the callus. However, this protocol for the induction of friable callus may have valuable applications for walnut and other woody trees.

\section{Acknowledgements}

This research was financially supported by Hubei Key Laboratory of Economic Forest Germplasm Improvement and Resources Comprehensive Utilization (20011BLKF239) and partly by the National Natural Science Foundation of China (No. 30900979).

\section{References}

Aftab F (2012). Progress and prospects for efficient micropropagation of woody plants, p. 363-377. In: Ashraf M, Öztürk M, Ahmad MSA, Aksoy A (Eds.). Crop Production for Agricultural Improvement. Springer, Netherlands.

Amiri ME (2006). Effect of mineral concentration on tissuecultured walnut (Juglans regia var. Zeiabadi) growth. Acta Hortic 705:383-386.

Amiri ME, Gharati S (2012). Influence of medium composition on multiplication of walnut (Juglans regia L.) growth. J Med Plants Res 6(8):1482-1485.

Avilés F, Ríos D, González R, Sánchez-Olate M (2009). Effect of culture medium in callogenesis from adult walnut leaves (Juglans regia L.) Chilean J Agric Res 69(3): 460-467.

Breton C, Cornu D, Chriqui D, Sauvanet A, Capelli P, Germain E, Jay-Allemand C (2004). Somatic embryogenesis, micropropagation and plant regeneration of "Early Mature" walnut trees (Juglans regia) that flower in vitro. Tree physiol 24(4): 425-435.

Cardoso JC, Martinelli AP, Latado RR (2012). Somatic embryogenesis from ovaries of sweet orange cv. Tobias. Plant Cell Tiss Organ Cult 109(1):171-177.

Chumakov MI, Moiseeva EM. Technologies of agrobacterium plant transformation in planta (2012). Appl Biochem Biotech 48(8):657-666.

Cummins JN, Ashby WC (1969). Aseptic culture of Juglans nigra stem tissues. For Sci 15:102-103.

Davey MR, Anthony P, Power JB, Lowe KC (2005). Plant protoplasts: status and biotechnological perspectives. Biotechnol Adv 23(2):131-171.

Driver JA, Kuniyuki, AH (1984). In vitro propagation of Paradox walnut Juglans hindsii $\times$ Juglans regia rootstock. Hort Sci 19:507-509.

Farsi M, Vahdati K, Lotfi M, Mirmasoumi M. (2012) Open the windows toward somatic embryogenesis of leaf explants of persian walnut (Juglans regia L.). Int J Nuts Related Sci 3(1):13-22.

Fatima A, Kamili AN, Shah AM (2006). Plantlet regeneration 
384 from excised embryonal axes, shoot apices, and nodal segments of Juglans regia L. Acta Hortic 705:387-392.

Fernández H, Pérez C, Sánchez-Tamés, R (2000). Modulation of the morphogenic potential of the embryonic axis of Juglans regia by cultural conditions. Plant Growth Regul 30(2):125-131

Gotea R, Gotea I, Sestras RE, Vahdati K (2012). In vitro propagation of several walnut cultivars. Bulletin UASVM Horticulture 69(1):167-171.

Leal DR, Sánchez-Olate M, Avilés F, Materan ME, Uribe M, Hasbún R, Rodríguez R (2007). Micropropagation of Juglans regia L, p. 381-390. In: Jain SM, Häggman H (Eds.) Protocols for micropropagation of woody trees and fruits. Springer, Heidelberg.

Lelu-Walter MA, Thompson D, Harvengt L, Sanchez L, Toribio M, Pâques LE (2013). Somatic embryogenesis in forestry with a focus on Europe: state-of-the-art, benefits, challenges and future direction. Tree Genet Genomes DOI 10.1007/ s11295-013-0620-1

Long LM, Preece JE, Van Sambeek JW (1995). Adventitious regeneration of Juglans nigra L. (eastern black walnut). Plant Cell Rep 14(12):799-803.

Neuman MC, Preece JE, Van Sambeek JW, Gaffney GR (1993). Somatic embryogenesis and callus production from cotyledon explants of Eastern black walnut. Plant Cell Tiss Organ Cult 32(1):9-18.

Payghamzadeh K, Kazemitabar SK (2010). The effects of BAP and IBA and genotypes on in vitro germination of immature walnut embryos. Inter J Plant Produc 4(4):309-322.

Payghamzadeh K, Kazemitabar SK (2011). In vitro propagation of walnut-A review. Afr J Biotechnol 10(3):290-311.

Prado MJ, Grueiro MP, González MV, Testillano PS, Domínguez C, López M, Rey M (2010). Efficient plant regeneration through somatic embryogenesis from anthers and ovaries of six autochthonous grapevine cultivars from Galicia (Spain). Scientia Hortic 125(3):342-352.

Rezaee R, Vahdati K, Grigoorian W, Valizadeh M (2008). Walnut grafting success and bleeding rate as affected by different grafting methods and seedling vigor. J Hortic Sci Biotechnol 83:94-99
San B, Dumanoglu H (2006). Somatic embryogenesis from immature cotyledons of apomictic and non-apomictic seeds in walnut (Juglans regia L.). Turk J Agric For 30(2):111-117.

Tang H, Ren Z, Krczal G (2000). Improvement of English walnut somatic embryo germination and conversion by desiccation treatment and plantlet development by lower medium salts. In Vitro Cell Dev Biol Plant 36:47-50.

Tang W, Newton RJ (2005). Plant regeneration from callus cultures derived from mature zygotic embryos in white pine (Pinus strobus L.). Plant Cell Rep 24(1):1-9.

Toosi S, Dilmagani K (2010). Proliferation of Juglans regia L. by in vitro embryo culture. J Cell Biol Genet 1(1):12-19.

Tulecke W, McGranahan G, Ahmadi H (1988). Regeneration by somatic embryogenesis of triploid plants from endosperm of walnut, Juglans regia L. cv Manregian. Plant Cell Rep 7(5):301-304.

Vahdati K, Bayat S, Ebrahimzadeh H, Jariteh M, Mirmasoumi $M$ (2008). Effect of exogenous ABA on somatic embryo maturation and germination in Persian walnut (Juglans regia L.). Plant Cell Tiss Organ Cult 93(2):163-171.

Vahdati K, Jariteh M, Niknam V, Mirmasoumi M, Ebrahimzadeh $\mathrm{H}$ (2006). Somatic embryogenesis and embryo maturation in Persian walnut. Acta Hortic 705:199-205.

Vahdati K, Razaee R, Mirmasoomi M (2009). Micropropagation of some dwarf and early mature walnut genotypes. Biotechnol 8:171-175.

von Arnold S, Sabala I, Bozhkov P, Dyachok J, Filonova L (2002). Developmental pathways of somatic embryogenesis. Plant Cell Tiss Organ Cult 69(3):233-249. 